\title{
6 OPEN ACCESS \\ Describing differences in weight and length growth trajectories between white and Pakistani infants in the UK: analysis of the Born in Bradford birth cohort study using multilevel linear spline models
}

\author{
Lesley Fairley, ${ }^{1}$ Emily S Petherick, ${ }^{1}$ Laura D Howe, ${ }^{2,3}$ Kate Tilling, ${ }^{3}$ Noel Cameron, ${ }^{4}$
} Debbie A Lawlor, ${ }^{2,3}$ Jane West, ${ }^{1}$ John Wright ${ }^{1}$

- Additional material is published online only. To view please visit the journal online (http://dx.doi.org/10.1136/ archdischild-2012-302778).

${ }^{1}$ Bradford Institute for Health Research, Bradford Teaching Hospitals NHS Foundation

Trust, Bradford, UK

${ }^{2}$ MRC Centre for Causal

Analyses in Translational Epidemiology, School of Social and Community Medicine, University of Bristol, Bristol, UK

${ }^{3}$ School of Social and Community Medicine, University of Bristol, Bristol, UK ${ }^{4}$ Exercise and Health Sciences, School of Sport, Loughborough University, Loughborough, UK

\section{Correspondence to} Lesley Fairley, Born in Bradford, Bradford Institute for Health Research, Bradford Teaching Hospitals NHS Foundation Trust, Bradford Royal Infirmary, Duckworth Lane,

Bradford BD9 6RJ, UK; Lesley.fairley@bthft.nhs.uk

Received 7 August 2012 Revised 15 January 2013 Accepted 21 January 2013 Published Online First 16 February 2013
To cite: Fairley $\mathrm{L}$, Petherick ES, Howe LD, et al. Arch Dis Child 2013;98:274-279.

\section{ABSTRACT}

Objective To describe the growth pattern from birth to 2 years of UK-born white British and Pakistani infants.

Design Birth cohort.

Setting Bradford, UK.

Participants 314 white British boys, 383 Pakistani boys, 328 white British girls and 409 Pakistani girls.

Main outcome measures Weight and length trajectories based on repeat measurements from birth to 2 years.

Results Linear spline multilevel models for weight and length with knot points at 4 and 9 months fitted the data well. At birth Pakistani boys were $210 \mathrm{~g}$ lighter $(95 \% \mathrm{Cl}-290$ to -120$)$ and $0.5 \mathrm{~cm}$ shorter $(-1.04$ to $0.02)$ and Pakistani girls were $180 \mathrm{~g}$ lighter ( -260 to $-100)$ and $0.5 \mathrm{~cm}$ shorter $(-0.91$ to -0.03$)$ than white British boys and girls, respectively. Pakistani infants gained length faster than white British infants between 0 and 4 months $(+0.3 \mathrm{~cm} /$ month $(0.1$ to 0.5$)$ for boys and $+0.4 \mathrm{~cm} /$ month (0.2 to 0.6$)$ for girls) and gained more weight per month between 9 and 24 months ( $+10 \mathrm{~g} /$ month ( 0 to 30 ) for boys and $+30 \mathrm{~g} /$ month (20 to 40) for girls). Adjustment for maternal height attenuated ethnic differences in weight and length at birth, but not in postnatal growth. Adjustment for other confounders did not explain differences in any outcomes.

Conclusions Pakistani infants were lighter and had shorter predicted mean length at birth than white British infants, but gained weight and length quicker in infancy. By age 2 years both ethnic groups had similar weight, but Pakistani infants were on average taller than white British infants.

\section{INTRODUCTION}

Growth during infancy is important to future health and well-being. ${ }^{1}$ Specific patterns of growth, such as rapid growth during infancy in children born with relatively low birth weights, are associated with cardiovascular disease. ${ }^{2}$ South Asian populations have a known higher risk of cardiometabolic disease, ${ }^{3}{ }^{4}$ a four to sixfold greater prevalence of diabetes and a 50\% higher risk of mortality from cardiovascular disease compared to the indigenous UK population. ${ }^{5}$

Childhood obesity is a growing public health problem; in England over a fifth of children start school overweight or obese, with the prevalence of obesity in children of South Asian origin being

\section{What is already known on this topic}

- Birth size and early childhood growth are important for normal development and short and long term health.

- Pakistani infants are lighter at birth than white British infants.

- The patterns of growth of UK Pakistani infants are largely unknown.

\section{What this study adds}

Pakistani boys and girls gain more length per month than white British children in the first 4 months of life.

- Pakistani boys and girls gain more weight per month after 9 months than white British children.

- By age 2 years Pakistani boys and girls have similar weight, but are generally taller than white British children.

higher than the national average. ${ }^{6}$ There is some evidence that risk of obesity is greater in those who grow more quickly/put on more weight from early life. ${ }^{7}{ }^{8}$ South Asian children are known to be among the lightest in the world at birth and to have a 'thin-fat' phenotype characterised by small abdominal viscera and low muscle mass but a relatively large proportion of body fat. ${ }^{9}$ This thin-fat phenotype persists during childhood, with several studies reporting higher skinfold values and more direct measurements of fat mass, for a given body mass, among South Asian compared with European samples. ${ }^{10-13}$

The growth patterns of South Asian infants and children have largely been explored through crosssectional studies. ${ }^{13-16}$ Traditional approaches to analysing child growth have used z scores, however this method does not allow the shape of the growth trajectory to be modelled or appropriately analyse the measurements which are clustered within individuals. Our aim is to compare the pattern of growth from birth to 2 years of age of white British and Pakistani infants. 


\section{DATA AND METHODS}

\section{Study population}

Born in Bradford (BiB) is a longitudinal multi-ethnic birth cohort study aiming to examine the impact of environmental, psychological and genetic factors on maternal and child health and well-being. ${ }^{17}$ Bradford is a city in northern England with high levels of socio-economic deprivation and ethnic diversity. Women were recruited at the Bradford Royal Infirmary at 2628 weeks gestation. A baseline questionnaire was completed for those consenting. The full $\mathrm{BiB}$ cohort recruited 12453 women comprising 13776 pregnancies between 2007 and 2010 and the cohort is broadly characteristic of the city's maternal population in terms of age, deprivation and ethnicity. ${ }^{17}$ Ethics approval for the study was granted by Bradford Research Ethics Committee (Ref 07/H1302/112).

A subsample of the $\mathrm{BiB}$ cohort (BiB 1000) recruited between August 2008 and March 2009 were invited to participate in follow-up examinations when their children were approximately 6, 12, 18 and 24 months of age. Of the 1917 women eligible for this substudy, 1735 consented and were included. Of these women, 1707 had a singleton birth and 28 had twin births. Twin births were excluded due to differences in growth patterns.

The mother's self-defined ethnicity was collected in the baseline questionnaire and used to define the ethnicity of her offspring. Analyses presented in this paper were restricted to the white British and Pakistani origin groups only as the numbers in the other ethnic groups were too small $(<75$ infants in each group) for further analysis.

\section{Measurements}

The baby's birth weight was obtained from hospital maternity records. For births that occurred outside the Bradford Royal Infirmary, this information was obtained from records held at Bradford and Airedale Primary Care Trust. Birth length was not routinely recorded.

Weight and length measurements between birth and 2 years of age were available from two sources: the $\mathrm{BiB} 1000$ clinics and health visitor records (which form part of standard care in the UK). The infants were visited at home or in clinics as part of the $\mathrm{BiB} 1000$ study at age 6, 12, 18 and 24 months; 1305 (76.5\%) of the sample completed the 6-month visit (age range at visit: 4.9-9.4 months), 1286 (75.4\%) the 12-month visit (age range at visit: $10.7-18.3$ months), $1263(74.0 \%)$ the 18 -month visit (age range at visit: 15.2-22.9 months) and 1201 (70.4\%) the 24-month visit (age range at visit: 23.4-28.5 months).

\section{Covariables}

Information on additional covariables was collected from the baseline questionnaire and birth records. The baby's sex and gestational age (preterm ( $<37$ weeks) or term ( $\geq 37$ weeks)) were collected from the birth record. Maternal smoking status was coded from self-report from the baseline questionnaire as smoker during pregnancy or non-smoker during pregnancy. Maternal height was measured at baseline. Overall, 24 participants had data missing on at least one of the covariables and were excluded from all growth models.

\section{Statistical analyses}

We estimated individual growth trajectories for weight and length from birth to 2 years of age using linear spline multilevel models (two levels: measurement occasion and individual), using the command 'runmlwin'18 in the software package Stata $11^{19}$ which calls the MLwiN V.2.4 software. $^{20}$ These models allow for the change in scale and variance in the measurements over time and use all available data under a missing at random assumption. They also allow for individual variation in growth trajectories, as random effects allow each individual to have different intercepts and slopes.

We fitted a series of models with knot points at different time intervals ( 3 and 9 months, 3 and 10 months, 3 and 12 months, 4 and 9 months, 4 and 10 months, and 4 and 12 months) based on the results of previous studies ${ }^{21-25}$ and selected the best fitting model as the model with the highest log likelihood. The model with knot points at 4 and 9 months was the best fitting model for these weight and length data.

Four coefficients for each of weight and length described the average growth trajectory in the cohort: birth weight/length and mean linear growth for the three time periods (birth4 months, 4-9 months and 9-24 months). Sex and ethnic differences in growth trajectories were estimated by fitting interaction terms between ethnic and sex groups (four groups: white British boys, Pakistani boys, white British girls and Pakistani girls), the constant term and each of the linear slopes (see the full equation in the supplementary material). The parameters for these interaction terms indicate whether there were differences in birth weight/length and growth in each time period between ethnic and sex groups.

Four growth trajectory models were fitted: unadjusted, adjusted for gestational age, adjusted for smoking during pregnancy, adjusted for maternal height and adjusted for all three additional covariables as fixed effects. Ethnicity, sex and measurement source were also included as level 1 random effects; sensitivity analyses were carried out including these only as fixed effects but the results did not change.

\section{RESULTS}

\section{Data and population}

Data on growth, ethnicity and all covariables were available for 314 white British boys, 383 Pakistani boys, 328 white British girls and 409 Pakistani girls (table 1). There was a median of seven weight measurements per child (IQR 6-9 measurements) and a median of four length measurements per child (IQR 3-5 measurements) (see supplementary web table S1). Model fit was good for all models (see online supplementary table S2).

\section{Ethnic differences in weight trajectories}

Figure 1 shows the predicted weight trajectory for each of the ethnic and sex groups. Pakistani boys and girls were lighter at birth on average than white British boys and girls (mean differences of $-210 \mathrm{~g}$ for boys (95\% CI -290 to -120 ) and $-180 \mathrm{~g}$ for girls $(95 \% \mathrm{CI}-260$ to -100$)$ ) (table 2). There were no ethnic differences in weight gain from birth to 4 months or between 4 and 9 months. Between 9 months and 2 years Pakistani boys and girls gained more weight per month than white British boys and girls: the unadjusted difference in weight gain per month was $10 \mathrm{~g}$ (95\% CI 3 to 30$)$ for boys and $30 \mathrm{~g}$ (95\% CI 20 to 40) for girls. By 2 years of age, the predicted weight for boys and girls was similar in both ethnic groups (see supplementary web table S3). Adjustment for maternal smoking increased the differences in birth weight by approximately $40 \%$, while adjustment for maternal height attenuated the difference by $57 \%$ for boys and $44 \%$ for girls, although this was negated in the fully adjusted model. Adjustment for the other covariables did not substantially alter the growth rates in each time period (table 2). 
Figure 1 Average weight $(\mathrm{kg})$ trajectory predicted by the multilevel models.

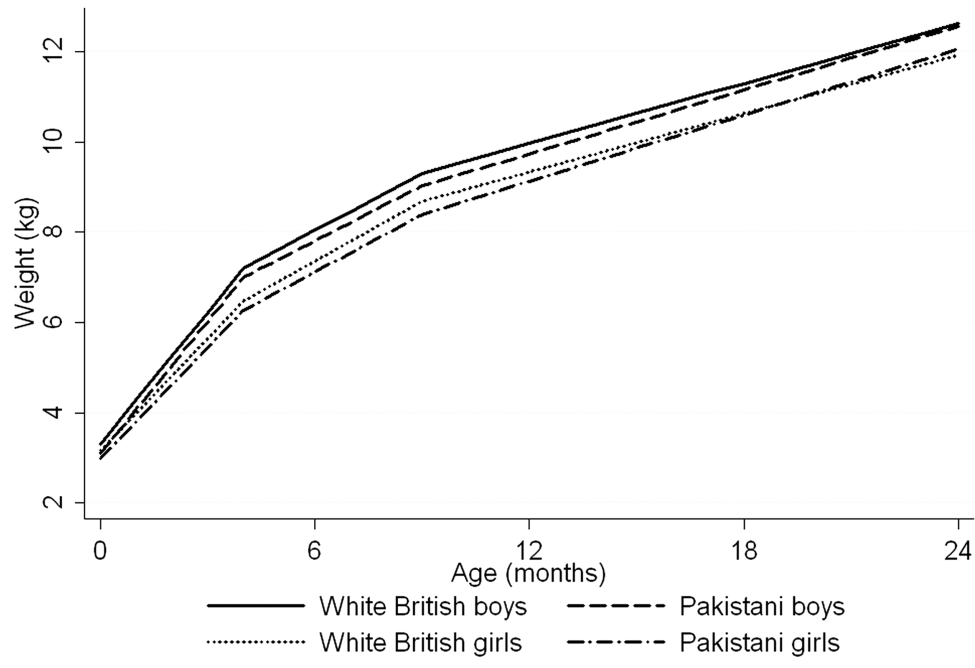

Ethnic differences in length trajectories

Figure 2 shows the predicted length trajectory for each of the ethnic and sex groups. Pakistani boys and girls had a shorter predicted mean length than white British boys and girls at birth: the mean predicted difference was $-0.51 \mathrm{~cm}(95 \% \mathrm{CI}-1.04$ to $0.02)$ for boys and $-0.47 \mathrm{~cm}(95 \% \mathrm{CI}-0.91$ to -0.03$)$ for girls (table 3). The growth rates in length between birth and 4 months were greater for both Pakistani boys and girls compared to white British boys and girls: the unadjusted difference in length gain was $0.31 \mathrm{~cm}$ per month $(95 \%$ CI 0.10 to 0.53$)$ for Pakistani boys compared to white British boys and $0.40 \mathrm{~cm}$ per month $(95 \%$ CI 0.20 to 0.59$)$ for Pakistani girls compared to white British girls (table 3). Between 4 and 9 months and 9 and 24 months, the rate of length gain was similar in all ethnic and sex groups. By 2 years of age Pakistani boys were $0.6 \mathrm{~cm}$ taller $(95 \%$ CI 0.02 to 1.21$)$ than white British boys and Pakistani girls were $1.1 \mathrm{~cm}$ taller (95\% CI 0.48 to 1.64 ) than white British girls (see supplementary web table S3). The ethnic differences in birth length increased by approximately $50 \%$ after adjustment for maternal smoking but were attenuated after adjustment for maternal height. Significant ethnic differences in birth length remained in the fully adjusted model. Adjustment for the additional covariables did not change differences in the growth rates in the other time periods investigated (table 3).

\section{DISCUSSION}

Pakistani boys and girls were lighter and had a shorter predicted mean length at birth than their white British counterparts. However by 2 years of age, the ethnic groups had similar weights but Pakistani boys and girls were taller. Differences in maternal height explained some of the differences in weight and length at birth, however adjustment for maternal height, smoking during pregnancy and gestational age did not explain the differences in postnatal growth rates.

Published data on the growth of healthy children in the first few years of life from Pakistan are scarce. ${ }^{26}{ }^{27}$ Growth centile charts for children born in Pakistan with normal birth weight, complete immunisation and no history of chronic infection aged 2-16 years have been developed. ${ }^{27}$ Our predicted mean values for weight and length at age 2 years for Pakistani boys and girls approximated the 50th centile values of these charts; however, these charts were based on small sample sizes so comparisons should be interpreted cautiously. A previous UK study found that South Asian boys showed greater increases in weight and length compared to European boys in the first 3 months of life, while growth rates were similar for girls of both ethnicities. ${ }^{28}$ In our study we found that in the first 4 months of life both Pakistani boys and girls had a greater increase in length, however no ethnic differences in weight gain were observed.

Table 1 Characteristics of study participants

\begin{tabular}{|c|c|c|c|c|c|}
\hline & All $(\mathrm{N}=1434)$ & White British boys ( $\mathrm{N}=314)$ & Pakistani boys $(\mathrm{N}=383)$ & White British girls $(\mathrm{N}=328)$ & Pakistani girls $(\mathrm{N}=409)$ \\
\hline \multicolumn{6}{|l|}{ Birth weight (kg) } \\
\hline Mean (SD) & $3.22(0.55)$ & $3.38(0.59)$ & $3.19(0.52)$ & $3.26(0.57)$ & $3.08(0.51)$ \\
\hline z Score $(S D)^{*}$ & $-0.22(1.21)$ & $0.00(1.26)$ & $-0.38(1.12)$ & $-0.00(1.28)$ & $-0.40(1.16)$ \\
\hline \multicolumn{6}{|l|}{ Weight at 2 years $(\mathrm{kg}) \dagger$} \\
\hline Mean (SD) & $12.45(1.54)$ & $12.75(1.50)$ & $12.81(1.45)$ & $12.16(1.41)$ & $12.16(1.66)$ \\
\hline z Score $(S D)^{*}$ & $0.32(1.01)$ & $0.29(1.01)$ & $0.33(1.02)$ & $0.34(0.98)$ & $0.32(1.04)$ \\
\hline \multicolumn{6}{|l|}{ Length at 2 years $(\mathrm{cm}) \dagger$} \\
\hline Mean (SD) & $86.6(3.4)$ & $87.3(3.6)$ & $87.3(3.1)$ & $85.4(3.4)$ & $86.4(3.2)$ \\
\hline z Score (SD)* & $-0.04(1.04)$ & $-0.06(1.14)$ & $-0.07(1.00)$ & $-0.20(1.04)$ & $0.11(1.00)$ \\
\hline$\%$ Smoked during pregnancy & 18.1 & 37.3 & 3.9 & 33.8 & 3.9 \\
\hline$\%$ Preterm birth & 5.4 & 7.0 & 4.4 & 5.5 & 4.9 \\
\hline Mean maternal height $\mathrm{cm}$ (SD) & $161.4(6.4)$ & $164.1(6.1)$ & $159.7(5.7)$ & $163.9(6.2)$ & $159.0(5.9)$ \\
\hline
\end{tabular}




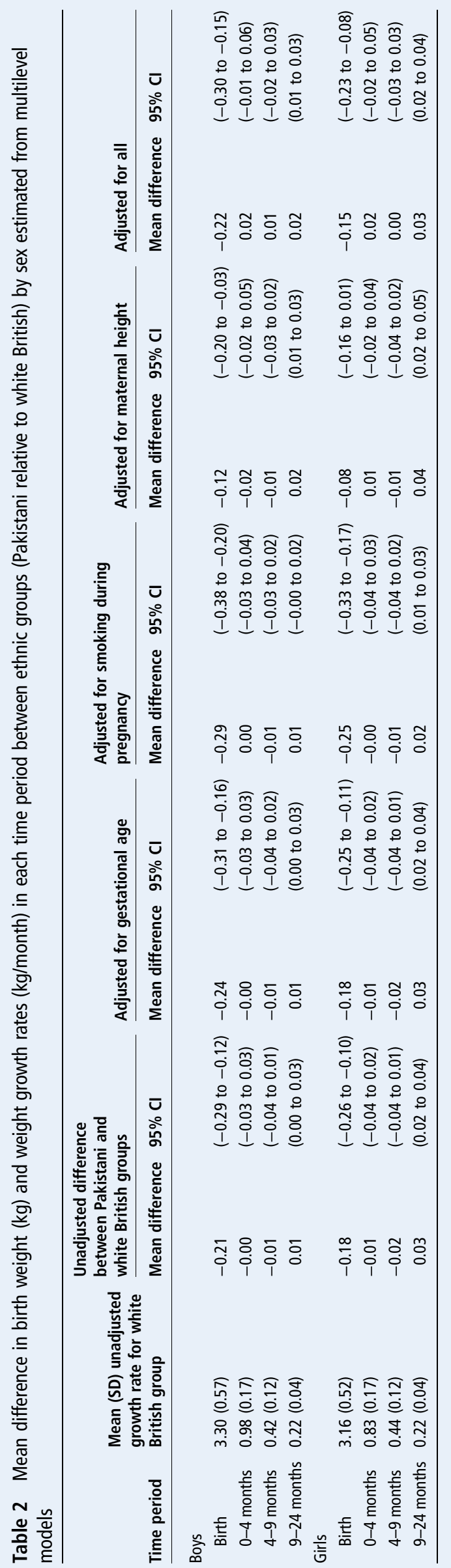



Figure 2 Average length $(\mathrm{cm})$ trajectory predicted by the multilevel models.

Given the relationship of early postnatal growth to normal development and adult health, together with known anthropometric differences at birth in South Asian compared to white European infants, it is important to understand how size differs in this group in the postnatal period, and what factors might explain these differences. The faster growth in South Asian children shown in our study could be beneficial for their early infant/childhood health as observed in low income countries. ${ }^{29}$ However, if the greater rate of weight gain is driven by greater fat gain in this population, it may have adverse long-term consequences for their cardiometabolic health ${ }^{30}$ and contribute to the increased risk of diabetes and cardiovascular disease observed in South Asian adults. ${ }^{3-5}$ South Asian children have been shown to be fatter for a given body mass index than their European counterparts and markers of diabetes and cardiovascular disease risk are increased in South Asian children and adolescents, suggesting that this faster early growth may indeed be contributing to adverse later cardiometabolic health. ${ }^{14}{ }^{15}{ }^{31}$ Although we acknowledge that further replication of our findings by others and longer term follow-up to examine associations with a range of early life and later outcomes will be required to clarify the importance of these ethnic differences in growth, further research is also needed to understand the genetic and environmental factors that might explain these differences.

\section{Strengths and limitations}

The main strengths of this study are that we modelled ethnic specific growth curves from birth to 2 years of age in a large sample size with repeat measurements of weight and length. The models fitted the data well and allowed us to derive very simple and interpretable associations between ethnicity and growth in infancy and make further adjustment for explanatory variables.

The knot points used to describe the periods of linear growth in this study are similar to those used to define the periods of linear growth in early infancy in a number of other cohort studies. ${ }^{21} 22-25$

One limitation of this study is that birth length is not routinely measured with $24 \%$ of infants being measured within the first 2 weeks and $48 \%$ within the first month. We have estimated birth length and ethnic differences from our growth models (ie, extrapolating back to birth), but these estimates may be unreliable. However, they are consistent with birth lengths reported in other studies. ${ }^{21-23}$ 


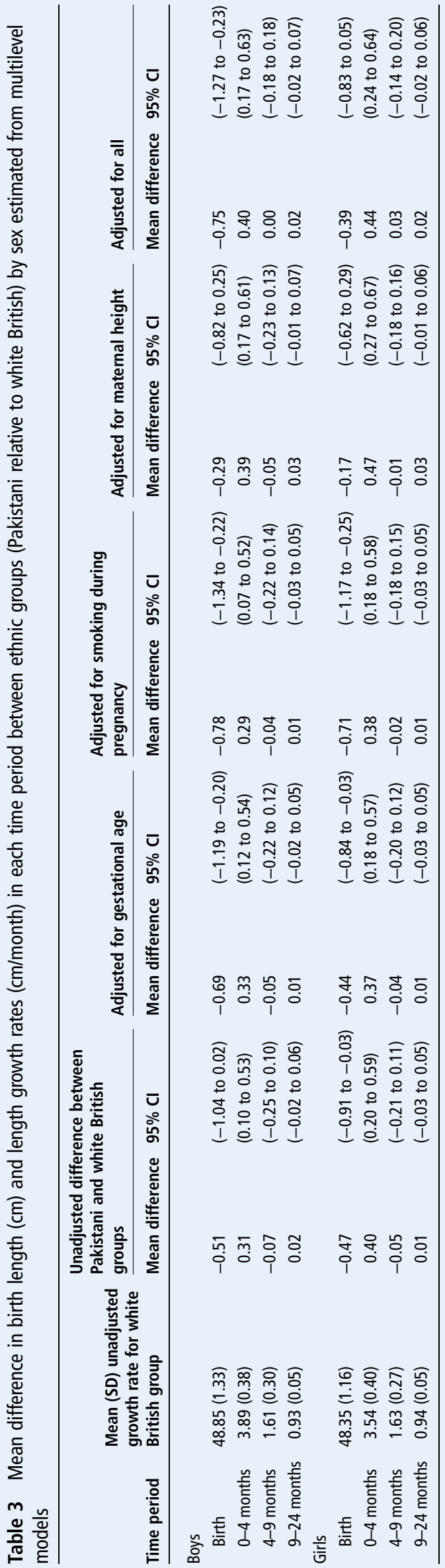

Another limitation is that the child is assigned the mother's self-reported ethnicity as we do not have information on the ethnic group of the child's father. However, the mother's and child's father's place of birth and birthplace of both sets of grandparents were obtained at interview. These data suggest that for over $90 \%$ of the Pakistani mothers, both of her parents and both parents of the child's father were born in South Asia.

As our study uses data from one UK geographical region, these results may not be generalisable to other areas even however, comparable growth trajectory data are not available for UK-born Pakistani infants.

\section{CONCLUSION}

Despite being lighter and having a shorter predicted mean length at birth, Pakistani boys and girls gained weight and length more quickly in infancy and by age 2 had similar weight and were taller than white British children. Replication of these findings in other studies and follow-up of this cohort to examine the relationship of this catch-up growth with short and longer term health outcomes is important.

Acknowledgements Born in Bradford is only possible because of the enthusiasm and commitment of the children and their parents. We are grateful to all the participants, health professionals and researchers who have made Born in Bradford happen.

Contributors J Wright, DAL and NC devised the study. LF, ESP, LDH, KT and DAL developed the analysis plan, and LF and ESP analysed the data with input from LDH and KT. LF and ESP drafted the manuscript. All authors contributed to data interpretation and to critical revisions of the manuscript.

Funding This paper presents independent research funded by the National Institute for Health Research (NIHR) under its Programme Grants for Applied Research (Grant Reference Number RP-PG-0407-10044). The views expressed are those of the author(s) and not necessarily those of the National Health Service (NHS), the NIHR or the Department of Health. LDH is funded by a UK Medical Research Council Population Health Scientist fellowship (G1002375). DAL and LDH work in a centre that receives funding from the University of Bristol and the UK Medical Research Council (G0600705).

Competing interests None.

Ethics approval Bradford Research Ethics Committee approved this study.

Provenance and peer review Not commissioned; externally peer reviewed.

Open Access This is an Open Access article distributed in accordance with the Creative Commons Attribution Non Commercial (CC BY-NC 3.0) license, which permits others to distribute, remix, adapt, build upon this work non-commercially, and license their derivative works on different terms, provided the original work is properly cited and the use is non-commercial. See: http://creativecommons.org/ licenses/by-nc/3.0/

\section{REFERENCES}

1 Cameron N, Demerath E. Critical periods in human growth: relationships to chronic disease. Yearbook Phys Anthropol 2002;45:159-84.

2 Gluckman PD, Hanson MA, Cooper C, et al. Effect of in utero and early-life conditions on adult health and disease. N Engl I Med 2008;359:61-73.

3 Health Survey for England, Department of Health. The health of minority ethnic groups '99. London, 2001.

4 Barnett AH, Dixon AN, Bellary $S$, et al. Type 2 diabetes and cardiovascular risk in the UK south Asian community. Diabetologia 2006;49:2234-46.

5 Balarajan R. Ethnicity and variations in mortality from coronary heart disease. Health Trends 1996:28:45-51.

6 The NHS Information Centre. National Child Measurement Programme, England 2010/2011 school year, 2011.

7 Shankaran S, Bann C, Das A, et al. Risk for obesity in adolescence starts in early childhood. J Perinatol 2011;31:711-16.

8 Tate AR, Dezateux C, Cole TJ. Is infant growth changing? Int I Obes (Lond) 2006:30:1094-96.

9 Yajnik CS, Fall CH, Coyaji KJ, et al. Neonatal anthropometry: the thin-fat Indian baby. The Pune Maternal Nutrition Study. Int I Obes Relat Metab Disord 2003;27:173-80.

10 Krishnaveni GV, Hill JC, Veena SR, et al. Truncal adiposity is present at birth and in early childhood in South Indian children. Indian Pediatr 2005;42:527-38. 
11 Gerver WJ, de BR. Body composition in children based on anthropometric data. A presentation of normal values. Eur J Pediatr 1996;155:870-76.

12 Joglekar CV, Fall CH, Deshpande VU, et al. Newborn size, infant and childhood growth, and body composition and cardiovascular disease risk factors at the age of 6 years: the Pune Maternal Nutrition Study. Int J Obes (Lond) 2007;31:1534-44.

13 Nightingale CM, Rudnicka AR, Owen CG, et al. Patterns of body size and adiposity among UK children of South Asian, black African-Caribbean and white European origin: Child Heart And health Study in England (CHASE Study). Int J Epidemiol 2011;40:33-44.

14 Whincup PH, Nightingale CM, Owen CG, et al. Early emergence of ethnic differences in type 2 diabetes precursors in the UK: the Child Heart and Health Study in England (CHASE Study). PLoS Med 2010;7:e1000263.

15 Whincup PH, Gilg JA, Papacosta 0, et al. Early evidence of ethnic differences in cardiovascular risk: cross sectional comparison of British South Asian and white children. BMJ 2002;324:635.

16 Saxena S, Ambler G, Cole TJ, et al. Ethnic group differences in overweight and obese children and young people in England: cross sectional survey. Arch Dis Child 2004:89:30-6.

17 Wright J, Small N, Raynor P, et al. Cohort profile: The Born in Bradford multi-ethnic family cohort study. Int J Epidemiol 2012. Published Online First: Epub Date. doi: dys112 [pii];10.1093/ije/dys112

18 Leckie G, Charlton C. Runm/win: Stata module for fitting multilevel models in the MLwiN software (program). Centre for Multilevel Modelling, University of Bristol, Bristol, 2011.

19 Statacorp. Stata Statistical Software release 11 (program). College Station, TX: StataCorp LP, 2009.

20 Rasbash J, Charlton C, Brown WJ, et al. MLwiN Version 2.24 (program). MLwiN Version 2.24 version: Centre for Multilevel Modelling. University of Bristol, Bristol, 2011
21 Howe LD, Tilling K, Galobardes B, et al. Socioeconomic differences in childhood growth trajectories: at what age do height inequalities emerge? J Epidemiol Community Health 2012:66:143-48.

22 Paternoster L, Howe LD, Tilling K, et al. Adult height variants affect birth length and growth rate in children. Hum Mol Genet 2011;20:4069-75.

23 Matijasevich A, Howe LD, Tilling K, et al. Maternal education inequalities in height growth rates in early childhood: 2004 Pelotas birth cohort study. Paediatr Perinat Epidemiol 2012;26:236-49.

24 Tilling K, Davies N, Windmeijer F, et al. Is infant weight associated with childhood blood pressure? Analysis of the Promotion of Breastfeeding Intervention Trial (PROBIT) cohort. Int J Epidemiol 2011;40:1227-37.

25 Tilling K, Davies NM, Nicoli E, et al. Associations of growth trajectories in infancy and early childhood with later childhood outcomes. Am J Clin Nutr 2011;94(6 Suppl):1808S-13S.

26 Aziz S, Puri DA, Hossain KZ, et al. Anthropometric indices of middle socio-economic class school children in Karachi compared with NCHS standards-a pilot study. J Pak Med Assoc 2006;56:264-67.

27 Aziz S, Noor-ul-Ain W, Majeed R, et al. Growth centile charts (anthropometric measurement) of Pakistani pediatric population. J Pak Med Assoc 2012;62:367-77.

28 Bansal N, Ayoola 00, Gemmell I, et al. Effects of early growth on blood pressure of infants of British European and South Asian origin at one year of age: the Manchester children's growth and vascular health study. J Hypertens 2008;26:412-18.

29 Victora CG, Adair L, Fall C, et al. Maternal and child undernutrition: consequences for adult health and human capital. Lancet 2008:371:340-57.

30 Singhal A, Lucas A. Early origins of cardiovascular disease: is there a unifying hypothesis? Lancet 2004;363:1642-5.

31 Ehtisham S, Crabtree N, Clark P, et al. Ethnic differences in insulin resistance and body composition in United Kingdom adolescents. J Clin Endocrinol Metab 2005:90:3963-9. 